\title{
A Randomized Double-Blind Trial Comparing the Efficacy of Dexamethasone vs. Clonidine as an Adjunct to Ropivacaine in Ultrasound Guided Continuous Interscalene Block for Arthroscopic Shoulder Surgery
}

\author{
Taneja $V^{1}$, Mitra $\mathrm{S}^{1 *}$, Singh J ${ }^{1}$, J indal $\mathrm{S}^{1}$ and Gupta \\ $\mathbf{R}^{2}$ \\ ${ }^{1}$ Department of Anaesthesia and Intensive Care, \\ Government Medical College and Hospital, Sector-32, \\ Chandigarh, India \\ ${ }^{2}$ Department of Orthopedics Government Medical College \\ and Hospital, Sector-32, Chandigarh, India \\ *Corresponding author: Sukanya Mitra, Department \\ of Anaesthesia and Intensive Care, Government Medical \\ College and Hospital, Sector-32, Chandigarh 160030, \\ India
}

Received: September 30, 2021; Accepted: October 26, 2021; Published: November 02, 2021

\begin{abstract}
Background: Ultrasound-Guided Continuous Interscalene Block (USGCISB) decreases postoperative morbidity following arthroscopic shoulder surgery. Both dexamethasone and clonidine have been shown to prolong the duration of analgesia when added with ropivacaine in peripheral nerve blocks. However, there is no head-to-head comparison between dexamethasone and clonidine as an adjuvant using USG-CISB.
\end{abstract}

Methods: In this randomized double-blinded controlled trial, 60 ASA grade 1-2 patients, 18-65 years, scheduled for arthroscopic shoulder surgery under general Anaesthesia following USG-CISB with perineural catheter using $30 \mathrm{ml}$ of $0.5 \%$ ropivacaine were randomly allocated to Group 1 (adjunct dexamethasone $8 \mathrm{mg}$ ) or Group 2 (adjunct clonidine $150 \mu \mathrm{g}$ ). Primary outcome was duration of postoperative analgesia, as measured (in min) from the achievement of adequate sensory block till the first bolus of $0.2 \%$ ropivacaine by patient controlled regional analgesia. Secondary outcomes were measures of the pain ratings, total postoperative analgesic consumption, patient satisfaction, and adverse effects over $48 \mathrm{~h}$ postoperatively.

Results: The median duration of analgesia in Group 1 was significantly longer than Group 2 (1432 min vs. $751 \mathrm{~min} ; \mathrm{P}<0.001)$. Median total postoperative analgesic consumption in Group 1 was significantly less than Group 2 (84 ml vs. $120 \mathrm{ml} ; \mathrm{P}<0.001)$. Median patient satisfaction score in Group 1 was significantly more than Group 2 (90 vs. $84 ; \mathrm{P}=0.001)$. Postoperative adverse effects were few and comparable.

Conclusion: Compared to clonidine, dexamethasone significantly prolonged the duration of analgesia, decreased postoperative analgesic consumption, and increased patient satisfaction following USG-CISB when used as an adjunct to ropivacaine for arthroscopic shoulder surgery.

Keywords: Analgesic; Adjunct; Dexamethasone; Clonidine; Ropivacaine; Utrasound guided continuous interscalene block; Arthroscopic shoulder surgery

\section{Introduction}

Pain after shoulder surgery can be intense. Any failure to relieve pain can produce harmful multisystem effects [1-5]. Uncontrolled pain is further associated with increased incidence of prolonged PostAnaesthesiaCare Unit (PACU) stay, delayed discharge, unanticipated hospital admissions and delayed resumption of normal activities [68]. Effective pain control should therefore be a critical component in the management of surgical outpatients to provide for an accelerated recovery, rehabilitation and optimal patient satisfaction.

Regional Anaesthesia (RA) in the form of Interscalene Block (ISB), either Single Shot (SSISB) or Continuous (CISB), is widely used for surgical Anaesthesia as well as for both postoperative and nonsurgical analgesia. Ultrasound Guidance (USG) has further increased the efficacy of ISB with improved safety margin due to better localization of the brachial plexus [9]. However, while SSISB may fail to provide adequate analgesia beyond sometime, CISB can be a better alternative as this technique provides better analgesia for prolonged durations leading to less analgesic gap [10]. Potential benefits of continuous peripheral nerve blocks include fewer side effects from systemic opioids, greater patient satisfaction, decreased time to adequate ambulation and faster functional recovery after surgery [10,11]. They also have the advantage of allowing optimization of both analgesia and motor function because total dose of Local Anesthetic (LA) can be controlled by the patient [12]. Evidence continues to be built as to optimal patient selection and surgical procedures for this modality.

Adjuvants added to LA hasten the onset of sensory-motor block, prolong the duration of sensory-motor block and limit the cumulative dose requirement of LA. Co-administration of adjuvants improve efficacy of perineural block and decrease Local Anesthetic Systemic Toxicity (LAST). Both dexamethasone and clonidine have
Austin J Anesthesia and Analgesia - Volume 9 Issue 2 - 2021 ISSN : 2381-893X | www.austinpublishing group.com Taneja et al. (C) All rights are reserved
Citation: Taneja V, Mitra S, Singh J, Jindal S and Gupta R. A Randomized Double-Blind Trial Comparing the Efficacy of Dexamethasone vs. Clonidine as an Adjunct to Ropivacaine in Ultrasound Guided Continuous Interscalene Block for Arthroscopic Shoulder Surgery. Austin J Anesthesia and Analgesia. 2021; 9(2): 1102. 


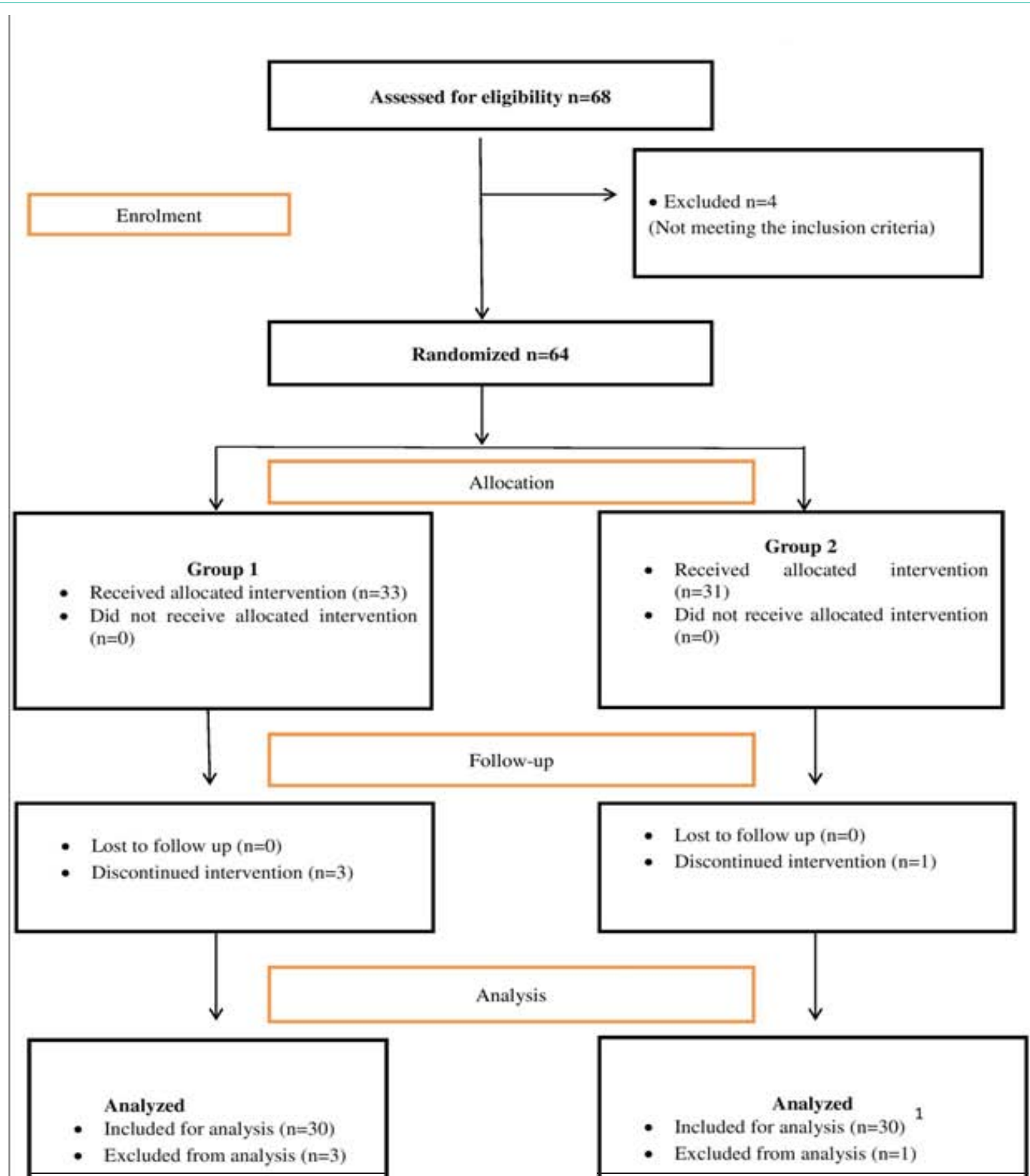

Figure 1: CONSORT diagram showing patient selection and randomization.

been independently shown to prolong the duration of analgesia when added with ropivacaine in Peripheral Nerve Blocks (PNBs) $[13,14]$. However, the average duration of each adjuvant when added, LA has been seen to last $22 \mathrm{~h}$ for $8 \mathrm{mg}$ dose of Dexamethasone (DXM) and 13 $\mathrm{h}$ for $150 \mu \mathrm{g}$ of Clonidine (CLO) respectively $[15,16]$.

So far there is no study comparing the efficacy of dexamethasone and clonidine in CISB in combination with ropivacaine for postoperative analgesia after arthroscopic shoulder surgery. The present study aims to compare the efficacy of dexamethasone and clonidine for postoperative analgesia, total postoperative analgesic consumption and patient satisfaction, and to determine the duration of block as an adjunct to ropivacaine in CISB when administered using USG. Also to produce seamless analgesia in the postoperative period, we plan to use CISB with perineural catheter with the provision of boluses by Patient Controlled Regional Analgesia (PCRA).

\section{Materials and Methods}

This double-blinded randomized controlled trial was conducted to evaluate the analgesic efficacy of dexamethasone vs. 
clonidine as an adjunct to ropivacaine in continuous USG-ISB for arthroscopic shoulder surgery. The trial was registered with the Clinical Trials Registry-India (CTRI; trial registration number CTRI/2017/02/007852, dated February 2, 2017). Patients were enrolled following CTRI registration from March 2017 till July 2018.

After obtaining approval from the Institutional Ethics Committee and written informed consent, 60 patients belonging to American Society of Anesthesiologists (ASA) physical status I and II, aged 18-65 years, Body Mass Index (BMI) $18-30 \mathrm{~kg} / \mathrm{m}^{2}$ of either sex admitted in hospital for elective arthroscopic shoulder surgery (rotator cuff injury repair and Bankart procedure for recurrent shoulder dislocations) were included in the study.

Patients refusing to give informed consent, patient with history of relevant drug allergy, psychiatric illness, substance abuse, severe cardiovascular, respiratory, metabolic or neurological disease, pregnancy and lactation, coagulopathy, contralateral phrenic nerve dysfunction, infection at planned injection site, patients receiving $\alpha-2$ agonists for hypertensive disorders and patients on steroids were excluded from the study.

Figure 1 shows the CONSORT flow diagram.

Patients were randomly allocated using computer generated random number table to one of the following groups using 60 coded opaque sealed envelopes:

Group I $(\mathrm{n}=30)$ Ultrasound guided ISB with $0.5 \%$ ropivacaine $30 \mathrm{ml}$ with $2 \mathrm{ml}$ of preservative-free DXM $8 \mathrm{mg}$ to a total of $32 \mathrm{ml}$.

Group II $(\mathrm{n}=30)$ Ultrasound guided ISB with $0.5 \%$ ropivacaine $30 \mathrm{ml}$ with $2 \mathrm{ml}$ of saline containing CLO $150 \mu \mathrm{g}$ to a total of $32 \mathrm{ml}$.

The study drugs were prepared in unlabeled identical looking syringes and were handed over to the anesthesiologist performing the block by a person not involved in this study. The patient and the investigator performing and assessing the ISB were blinded to the study drug.

Preoperatively, a complete preanesthetic evaluation and investigations were performed for all the patients. They were explained about the use of PCRA, linear Visual Analogue Scale (VAS) for pain (0-no pain, 10-worst imaginable pain) and categorical scoring system for nausea (0-none, 1-mild, 2-moderate, 3-severe) in their own vernacular language. Patients were kept fasting for $6 \mathrm{~h}$ minimum and were premedicated with tablet ranitidine $150 \mathrm{mg}$ and tablet alprazolam $0.25 \mathrm{mg}$ orally on the night before surgery and at $6 \mathrm{am}$ on the morning of surgery.

\section{Description of procedure}

The block was performed in the Operating Room (OR). The patient was explained about the procedure before performance of the block. Oxygen supplementation was provided by nasal prongs in all the patients. Patient was connected to a multichannel monitor (GE Healthcare Helsinki, Finland) and monitored for Electrocardiogram (ECG) and Pulse Rate (PR), Non-Invasive Arterial Blood Pressure (NIBP) and Oxygen Saturation $\left(\mathrm{SpO}_{2}\right)$. An intravenous (i.v.) infusion of normal saline at rate of $2 \mathrm{ml} / \mathrm{kg} / \mathrm{h}$ was started after inserting $18 \mathrm{G}$ peripheral i.v. cannula. An USG-ISB was performed as per group allocation. The study drugs were administered as per randomisation.
The procedure was performed in head up position with head rotated towards the non-operative side. After ensuring full aseptic conditions and draping the area, local infiltration of skin was performed with $2 \%$ lidocaine. A high frequency (7-13 MHz) US probe (Sonosite, Inc. Bothell, WA 98021 USA) was placed transversely at the level of cricoid cartilage. The transducer was moved laterally towards the operative side to identify carotid artery and internal jugular vein. Further lateral, anterior scalene and medial scalene muscles were identified on US. The roots of the brachial plexus were identified between the two muscles as three hyperechoic vesicles lying in close proximity with each other. Under continuous in-plane USG, the needle was directed anteriorly toward the brachial plexus, passing through the middle scalene muscle. Study drugs were then deposited under USG as per group allocation in a blinded manner. This was noted as $0 \mathrm{Hr}$. A $19 \mathrm{G}$ catheter was then placed through the length of the needle and was introduced $5 \mathrm{~cm}$ beyond the needle tip. The needle was then withdrawn over the catheter and the catheter stylet was removed and catheter was fixed on the contralateral shoulder using transparent aseptic dressing.

After injection of the designated LA mixture, patients were evaluated at $2 \mathrm{~min}$ interval for 20 minutes for development of sensory and motor block. Sensory block was assessed by loss of sensation to pinprick over the deltoid muscle. It was assessed using a 3 point scale to pinprick with a toothpick (pinprick to shoulder; 0: normal sensation, 1: sharp to pinprick, 2: pinprick felt but not sharp, 3: no sensation with pinprick not felt). The time to achieve adequate sensory block was noted. Motor block was assessed by failure to abduct the shoulder, the so called "deltoid sign" ( 0 , normal abduction; 1 , decreased movement, moves shoulder but not normal; 2 , unable to abduct shoulder).

After assessing for the sensory and motor blockade at the intervals as prescribed in the intake form, all the patients were administered General Anaesthesia (GA).

All patients received a standard GA technique. Induction was done using i.v. glycopyrrolate $0.2 \mathrm{mg}$, i.v. fentanyl $2 \mu \mathrm{g} / \mathrm{kg}$, i.v. Propofol $2 \mathrm{mg} / \mathrm{kg}$ and i.v. vecuronium $0.1 \mathrm{mg} / \mathrm{kg}$ to facilitate endotracheal intubation. Anaesthesiawas maintained with $\mathrm{N}_{2} \mathrm{O}: \mathrm{O}_{2}$ in a ratio of 60:40 with isoflurane (inspired concentration of $0.5 \%$ - 2\%). After ensuring bilateral air entry, surgical procedure was allowed to proceed. There was provision to supplement fentanyl intraoperatively in the dose of $1 \mu \mathrm{g} / \mathrm{kg}$ if there was $20 \%$ increase from the baseline parameters. After the induction of anesthesia, End Tidal Carbon Dioxide $\left(\mathrm{EtCO}_{2}\right)$ was also monitored in addition to the above parameters.

Fifteen minutes before completion of surgery, injection ondansetron $0.1 \mathrm{mg} / \mathrm{kg}$ was given to all patients. At the end of the procedure, the residual neuromuscular block was reversed with i.v. neostigmine $50 \mu \mathrm{g} / \mathrm{kg}$ and glycopyrrolate $10 \mu \mathrm{g} / \mathrm{kg}$ i.v. Subsequently trachea was extubated and patients were shifted to PACU.

The inserted $19 \mathrm{G}$ catheter in the interscalene groove of the patient was connected to PCRA (Master PCA, Fresenius Kabi, Finland) in PACU providing $0.2 \%$ ropivacaine as analgesic. The pump was set to deliver $4 \mathrm{ml}$ of patient controlled boluses of $0.2 \%$ ropivacaine, with lock out interval set at $30 \mathrm{~min}$. Time to first bolus was noted 
to determine the duration of ISB. Number of Boluses (NOB) taken during the study period and any adverse effects were also noted. Patient satisfaction was noted at the end of $48 \mathrm{~h}$ study period.

\section{Data Collection}

Data were collected for $48 \mathrm{~h}$ after the nerve block.

Demographic (age, gender, comorbidities) and morphometric (height, weight) characteristics of participating patients were recorded. Patients were continuously monitored for NIBP, ECG, Heart Rate (HR), $\mathrm{SpO}_{2}, \mathrm{EtCO}_{2}$ and Respiratory Rate (RR). After induction, all the patients were monitored for hemodynamic variables at regular intervals. Initially the parameters were assessed every 5 min till 20 min and then after every 20 min till the completion of the surgery. Postoperatively, the patients were kept in PACU and pain was assessed using Visual Analogue Scale (VAS) and nausea and or vomiting were assessed using categorical scoring system. All the observations (age, sex, vital parameters) including VAS for pain, categorical scoring system for nausea and or vomiting, total analgesic requirements, total antiemetic requirement and occurrence of any adverse effects were recorded. Also, at the end of the $48 \mathrm{~h}$ study period patient satisfaction score was recorded on 0-100 VAS Scale.

\section{Primary outcome}

Duration of postoperative analgesia, as measured in minutes from the achievement of adequate sensory block till the first bolus of $0.2 \%$ ropivacaine by PCRA.

\section{Secondary outcome}

Measures pain ratings over $48 \mathrm{~h}$ on 0 -10 VAS, total postoperative analgesic consumption, patient satisfaction, and any adverse effects. The sedation in two groups was assessed at $6 \mathrm{~h}$ after the nerve block using Ramsay Sedation Scale (RSS) [17]. RSS scores on sedation are marked on a 6-point scale on increasing levels of sedation, 1 being "patient anxious or agitated or both," and 6 being "no response to light, glabellar tap, or loud auditory stimulus." A score of 3 or more is considered as indicative of sedation.

\section{Sample Size Calculation}

Because almost all patients require analgesics after shoulder procedures, sample size estimation assumed no censoring of block durations. The study was designed to have $80 \%$ power to detect clinically important interactions and main effects for the primary outcome of block duration. Previous studies have shown the duration of analgesia of ropivacaine to be around 800 minutes (min) (SD, 250 ) for a $20 \mathrm{ml} \mathrm{ISB}$ with $0.5 \%$ ropivacaine alone. A $25 \%$ increase in duration of analgesia due to addition of either of the two study drugs (i.e., $800+200=1000 \mathrm{~min}$ ) was deemed clinically significant. With this assumption, a sample size of 25 subjects in each group would have $80 \%$ power to detect a difference in means of $200 \mathrm{~min}$, assuming equal variance using a 2 group $t$ test with a 0.05 two sided significance level. The study was designed to enroll total of 60 subjects keeping in mind the possible drop outs, if any (30 per group).

\section{Statistical analysis}

The statistical analysis was carried out using Statistical Package for Social Sciences (SPSS Inc., Chicago, IL, version 17.0 for Windows). The primary outcome of duration of postoperative analgesia, as measured (in minutes) by the time from the achievement of adequate sensory block till the first use of $0.2 \%$ ropivacaine bolus by PCRA, was analysed using a survival analysis (Cox model). Kaplan Meier curve was used for measuring the duration of analgesia. Continuous variables were tested for normal distribution using KolmogorovSmirnov test. To test for significance of difference between the two groups on single measure data (patient satisfaction score at the end of $48 \mathrm{~h}$ study period, and total postoperative analgesic consumption till $48 \mathrm{~h}$ postoperatively), between group comparisons were performed using a Student's test for normally distributed continuous variables, Mann-Whitney $U$ test for non-normally distributed continuous variables, chi square test for binary variables, and Wilcoxon test for ordered categorical variables. For repeated measures data assessment over time, including pain scores at rest and with activity, postoperative sensory and motor scores, heart rate, and blood pressure, two-way repeated measures ANOVA with post hoc Scheffe's test were used for analysis. Significance level was set at 0.05 .

\section{Results}

There was no statistical difference in the two groups with respect to age, sex, height, gender, weight, BMI, type and duration of surgery (Table 1). There was no significant difference in relation to preoperative investigations and vital parameters. Time to onset of sensory and motor block was clinically significant. Sensory block onset for group 1 was $12.80 \pm 1.27 \mathrm{~min}$ and for group 2 was $10.20 \pm$ $1.90 \mathrm{~min}$ ( $\mathrm{p}$ value $<0.001$ ) (Table 1 ). Motor block onset for group 1 was $18.73 \pm 1.04 \mathrm{~min}$ and for group 2 was $14.83 \pm 1.64 \mathrm{~min}$ ( $\mathrm{p}$ value $<0.001$ ) (Table 1).

The intraoperative mean HR compared between the two groups at $0 \mathrm{~min}, 5 \mathrm{~min}, 10 \mathrm{~min}, 15 \mathrm{~min}$ and $20 \mathrm{~min}$ was statistically significant ( $\mathrm{p}$ value $<0.05$ ). The intraoperative mean systolic blood pressure at $0 \mathrm{~min}, 10 \mathrm{~min}, 15 \mathrm{~min}$ and mean diastolic blood pressure at $5 \mathrm{~min}, 10 \mathrm{~min}$ when compared between the two groups were statistically significant( $\mathrm{p}$ value $<0.05$ ). The intraoperative respiratory rate compared between the two groups was statistically insignificant. The difference in mean postoperative HR, systolic blood pressure, diastolic blood pressure and respiratory rate were not significant between the two groups when compared with the baseline.

With regard to the primary outcome measure, the median duration of analgesia (Interquartile Range [IQR]) for group 1 was

Table 1: Comparison of patient characteristics in the two groups.

\begin{tabular}{|c|c|c|c|}
\hline \multirow{2}{*}{ Characteristics } & Group 1 & Group 2 & \multirow{2}{*}{ P Value } \\
\hline & $\begin{array}{c}\text { (DEXAMETHASONE) } \\
\qquad \mathrm{N}=30\end{array}$ & $\begin{array}{c}\text { (CLONIDINE) } \\
\mathrm{N}=30\end{array}$ & \\
\hline Age (years) & $29.90 \pm 12.60$ & $28.40 \pm 10.34$ & 0.616 \\
\hline Male & $24(80 \%)$ & $27(90.0 \%)$ & 0.27839 \\
\hline Female & $6(20 \%)$ & $3(10 \%)$ & 0.739 \\
\hline Weight (kg) & $67.90 \pm 5.20$ & $69.20 \pm 4.20$ & 0.29 \\
\hline Height (cm) & $172.96 \pm 6.35$ & $175.23 \pm 4.41$ & 0.114 \\
\hline $\begin{array}{l}\text { Body mass index } \\
\qquad\left(\mathrm{kg} / \mathrm{m}^{2}\right)\end{array}$ & $22.75 \pm 1.90$ & $22.58 \pm 1.66$ & 0.734 \\
\hline $\begin{array}{l}\text { Duration of surgery } \\
\text { (in minutes) }\end{array}$ & $48.70 \pm 10.07$ & $48.23 \pm 12.94$ & 0.558 \\
\hline $\begin{array}{l}\text { Sensory block } \\
\text { (in minutes) }\end{array}$ & $12.80 \pm 1.27$ & $10.20 \pm 1.90$ & $<0.001$ \\
\hline $\begin{array}{l}\text { Motor block } \\
\text { (in minutes) }\end{array}$ & $18.73 \pm 1.04$ & $14.83 \pm 1.64$ & $<0.001$ \\
\hline
\end{tabular}

Data presented as mean \pm standard deviation or number (\%). 
Table 2: Comparison of duration of analgesia, total number of boluses, total analgesic consumed, and patient satisfaction in the two groups.

\begin{tabular}{|c|c|c|c|}
\hline & $\begin{array}{c}\text { Group 1 } \\
\text { (DEXAMETHASONE) } \\
\mathbf{N = 3 0}\end{array}$ & $\begin{array}{c}\text { Group 2 } \\
\text { (CLONIDINE) } \\
\mathbf{N = 3 0}\end{array}$ & P Value \\
\hline Duration of analgesia & $1432(1338-1510)$ & $751(674-822)$ & $<0.001$ \\
\hline Total number of boluses & $0(0-4)$ & $2(0-4.5)$ & $<0.001$ \\
\hline $\begin{array}{c}\text { Total analgesic } \\
\text { consumption }\end{array}$ & $84(55-96)$ & $120(91-128)$ & $<0.001$ \\
\hline $\begin{array}{c}\text { Patient satisfaction } \\
\text { score }\end{array}$ & $90.00(85.50-92.00)$ & $\begin{array}{c}84.00(77.50- \\
90.00) .\end{array}$ & $<0.001$ \\
\hline \multicolumn{2}{|l|}{ Data presented as median (Interquartile Range [IQR]). } \\
\hline
\end{tabular}

$1432 \mathrm{~min}(\mathrm{IQR}=1338-1510)$ and for group 2 was $751 \mathrm{~min}(\mathrm{IQR}=$ 674-822). The comparison of duration of analgesia in the two groups using Mann-Whitney $\mathrm{U}$ test was statistically significant $(\mathrm{p}<0.001)$ and it showed that group 1 had significantly longer duration of analgesia than group 2 (Table 2).

Total number of boluses used in $48 \mathrm{~h}$ was significantly more in group 2 (median $=2, \mathrm{IQR}=0-4.5)$ as compared to group 1 (median $=0, \mathrm{IQR}=0-4)$. The difference between two groups was statistically significant when compared using Mann-Whitney U test (Table 2).

Median (IQR) total analgesic consumption for group 1 was 84 (55-96) and for group 2 was 120 (91-128) and was statistically significant on Mann Whitney U test $(\mathrm{p}<0.001)$ (Table 2).

The median (IQR) VAS-Satisfaction score for group I was 90.00 (85.50-92.00) and for group II was 84.00 (77.50-90.00). The difference compared among the two groups on Mann-Whitney $U$ test was statistically significant (p-0.001) (Table 2 ).

Two-way ANOVA showed significant difference between the two groups regarding VAS pain scores on rest (F value 14.232; $\mathrm{P}<$ 0.001 ) and on movement ( $\mathrm{F}$ value 20.416; $\mathrm{P}<0.001$ ). Also within each group the differences across various time points of observation were significant on rest $(\mathrm{F}$ value 14.232; $\mathrm{P}<0.001)$ and on movement $(\mathrm{F}$ value 20.416; $\mathrm{P}<0.001)$. On application of post-hoc Scheffe's test, VAS pain scores at Rest (VAS-R) were comparable to baseline (Time $4 \mathrm{~h}$ ) for all time points of observation till $10 \mathrm{~h}$ post block; after that the pain scores became significantly lower in dexamethasone group as compared to clonidine group. Similar results were observed for the VAS pain scores on movement (VAS-M) as well. Group $\mathrm{x}$ time interaction was significant for both VAS-R (F value 14.232; $\mathrm{P}<0.001$ ) and VAS-M (F value 20.416; $\mathrm{p}<0.001$ ), confirming the differential pattern of pain relief over time in the two groups.

Median (IQR) patient satisfaction score for group 1 was 90.00 (85.50-92.00) and for group 2 was 84.00 (77.50-90.00). The difference compared among the two groups on Mann-Whitney $U$ test was statistically significant $(\mathrm{p}=0.001)$. (Table 2 )

No episodes of nausea/vomiting, dizziness, vertigo, hypoxemia, decreased respiratory rate, or bradycardia was seen within $48 \mathrm{~h}$ postoperatively. Three patients (10\%) in group 2 experienced hypotension till $4 \mathrm{~h}$ postoperatively with none having hypotension in group 2. More patients in group 2 were sedated as compared to group 1 (3 patients in group 2 scored 3 or more on RSS compared to none in group 1) though the difference was not statistically significant ( $\mathrm{p}=$ 0.308). Three patients scored 3 and three scored 2 (in group 2), and none scored 5 or 6 (deep sedation) while one patient scored 2 and none scored 3 or more in group 1. Horner's syndrome and hoarseness of voice were seen among both the groups. Equal incidence of Horner's syndrome was seen in both the groups with 3 patients in group $1(10 \%)$ and group $2(10 \%)$. Hoarseness of voice was seen in two patients in group 1 (6.66\%) and in one patient in group 2 (3.33\%). No other adverse effects were noted.

\section{Discussion}

In the present study, the total duration of analgesia at $48 \mathrm{~h}$ postoperatively was significantly more in patients of CISB with $0.5 \%$ ropivacaine plus dexamethasone group as compared to patients of CISB with $0.5 \%$ ropivacaine plus clonidine group. Dexamethasone group has [median (IQR)] 1432 (1338-1510) min and clonidine group has 756 (674-822) min as duration of analgesia [median (IQR)]. There was also provision of PCRA with perineural ropivacaine $0.2 \%$ as a rescue analgesic for postoperative pain relief within the study period. Total ropivacaine consumption [median (IQR)] by PCRA was $84 \mathrm{ml}$ (55-96) in dexamethasone group and $120 \mathrm{ml}$ (91-129) in clonidine group. The difference in both the duration of analgesia and the ropivacaine consumption by PCRA was statistically significant between the two groups.

The findings of present study are in line with the existing literature which shows that addition of dexamethasone as an adjuvant to LA increases the duration of analgesia $[13,15]$. The literature so far has a few randomized clinical trials estimating the duration of analgesia with ropivacaine in conjunction of dexamethasone or clonidine as an adjunct. However, there is no head to head comparison of dexamethasone or clonidine when used as an adjunct with $0.5 \%$ of ropivacaine for USG CISB with a perineural catheter for postoperative pain relief.

There are a number of studies in the current literature where CISB was performed using $20-40 \mathrm{ml}$ of $0.5 \%$ to $0.75 \%$ ropivacaine or bupivacaine $[18,19]$ followed by continuous infusion of perineural ropivacine for prolonged pain relief $[11,12,18,20,21]$. In this study, $30 \mathrm{ml}$ of $0.5 \%$ ropivacaine was used with $8 \mathrm{mg}$ dexamethasone and the result showed that median duration of analgesia was $1424 \mathrm{~min}$ and found to be increased in comparison to the previous studies. The increase can be attributed to better localization of brachial plexus and drug deposition under direct visualization using real time USG. Desmet et al. used $0.5 \%$ of $30 \mathrm{ml}$ ropivacaine with $10 \mathrm{mg}$ dexamethasone and duration of analgesia was found to be $23 \mathrm{~h}$ [13]. Cummings et al. used $0.5 \%$ of $30 \mathrm{ml}$ ropivacaine with $8 \mathrm{mg}$ dexamethasone and duration of analgesia was $22.4 \mathrm{~h}$ [15]. Kawanishi et al. similarly used $0.75 \%$ of 20 $\mathrm{ml}$ ropivacaine with $4 \mathrm{mg}$ dexamethasone and duration of analgesia was $18 \mathrm{~h}[22]$.

Although incompletely understood, dexamethasone prolongs block duration by increasing the activity of inhibitory potassium channels on nociceptive $\mathrm{C}$ fibers or by causing vasoconstriction via glucocorticoid receptor mediated nuclear transcription modulation $[23,24]$. Other mechanisms include local vasoconstrictive effect, resulting in reduced local LA absorption [24,25]. or a systemic anti-inflammatory effect following vascular uptake of the drug [13]. Studies have suggested a systemic effect is responsible for its clinical effect and i.v. administration gives similar results [13]. Regardless of its specific mechanism, the best evidence suggests its action is via indirect mechanisms rather than by directly inhibiting 
neurotransmission [26].

The route of dexamethasone administration has been debated in the past and several studies have reported that i.v. dexamethasone can produce rescue analgesic sparing effects and that there was no difference in the analgesic effect between perineural and systemic administration [13]. This reduces the probability that dexamethasone exerts its action by a direct perineural effect. Kawanishi et al. concluded that perineural and not systemic dexamethasone prolongs the duration of analgesia [22]. A meta-analysis suggested i.v. dexamethasone at doses less than $0.1 \mathrm{mg} / \mathrm{kg}$ did not produce an opioid sparing effect and only doses higher than $0.1 \mathrm{mg} / \mathrm{kg}$ was effective as adjuvant [27]. In the present study, $8 \mathrm{mg}$ dexamethasone was used as an adjunct.

Animal studies showed no long term changes in nerve structure or function after local steroid administration [23]. The neurological risk with use of dexamethasone appears to be small [28].

In the present study, $0.5 \%$ ropivacaine was used with $150 \mu \mathrm{g}$ of clonidine with duration of analgesia to be $751.4 \pm 101.4 \mathrm{~min}$. El Saied et al. concluded that the addition of $150 \mu \mathrm{g}$ of clonidine to ropivacaine, for brachial plexus blockade, prolongs motor and sensory block and analgesia, without an increased incidence of side effects [16] Murphy et al. on the basis of six trials concluded that clonidine in doses up to $150 \mu \mathrm{g}$ increased the duration of postoperative analgesia with minimal adverse effects [29]. Popping et al. concluded that adding clonidine to intermediate or long acting LA for single shot peripheral nerve or plexus blocks prolonged duration of analgesia by $123 \mathrm{~min}$ and motor block by $141 \mathrm{~min}$ [14]. Bernard et al. stated that clonidine produces dose dependent prolongation of analgesia [30]. In this study, duration of analgesia is in accordance to the previous studies.

Clonidine produces analgesia by acting on the large number of alpha- 2 receptors present in central nervous system, at locus ceruleus and dorsal horn of the spinal cord leading to centrally mediated sedation and analgesia [31]. It also enhances or amplifies the sodium channel blocking action of LAs by opening up of the potassium channels resulting in hyperpolarization making cell unresponsive to excitation input [32].

Onset of sensory block in dexamethasone group was $12.80 \pm 1.27$ $\mathrm{min}$ and $10.20 \pm 1.90 \mathrm{~min}$ in clonidine group. Motor block onset was $18.73 \pm 1.04 \mathrm{~min}$ in dexamethasone and $14.83 \pm 1.64 \mathrm{~min}$ in clonidine group respectively. The findings are significant between two groups. Studies have documented time to sensory blockade to be $12.24 \pm$ $1.88 \mathrm{~min}$ when dexamethasone is added to ropivacaine and $8.05 \pm$ 3.21 min when clonidine is added to ropivacaine in PNBs [33,34]. In comparison where dexamethasone has no effect on the time to onset of sensory block, clonidine significantly shortens the time to onset of sensory block $[14,33]$. Both dexamethasone and clonidine individually have no effect on motor block onset and increase the duration of analgesia $[14,16,33]$.

In the present study, mean VAS scores on rest and on movement have been noted and it is reduced in dexamethasone group as compared to clonidine group. Singelyn et al. and Jadon et al. Showed that dexamethasone and clonidine reduce the VAS scores and demand for rescue analgesic when added to ropivacaine $[33,35]$. There was provision of PCRA for breakthrough pain. Perineural ropivacaine
(0.2\%) consumed for breakthrough pain in the study period by the two study groups were $84 \mathrm{ml}$ (55-96) in dexamethasone and $120 \mathrm{ml}$ (91-128) in clonidine respectively. The difference in consumption of rescue analgesic was statistically significant.

The median (inter-quartile range) patient satisfaction score for group I was $90.00(85.50-92.00)$ and 84.00 (77.50-90.00) for group II. The difference when compared among both the groups was statistically significant. This comparison could be because to clonidine group having earlier onset of pain with breakthrough pain starting after a mean duration of 12.5 hours. All the patients were satisfied with the analgesic technique and use of PCRA as evidenced by the patient satisfaction scores. However, patient satisfaction is a complex multidimensional phenomenon involving physical, emotional and psychosocial factors and the similarity in the patient satisfaction score cannot be solely due to the adequate pain relief.

In this study visual analogue scale was used to assess pain scores at frequent intervals. It has been seen that visual analogue scale is more sensitive and potentially superior when assessing acute pain [34].

The difference in the demographic parameters was non-significant. The intraoperative hemodynamic parameters between the two groups were statistically not significant. In intragroup comparison, there was statistically significant difference in the mean intraoperative heart rate, mean intraoperative systolic blood pressure and mean intraoperative diastolic blood pressure from the baseline. This could be due to dose dependent adverse effects of clonidine with application of hypotensive Anaesthesia in shoulder arthroscopy surgeries. Postoperatively, three patients in the clonidine group had low blood pressure for four hours which did not require any intervention. The low blood pressure in these patients can be attributed to combined effect of clonidine with application of hypotensive Anaesthesia leading to hypotension in postoperative period. Rest all the hemodynamic parameters values were within the normal physiological limits and were statistically not significant.

Only three patients had hoarseness of voice and six developed Horner's Syndrome (HS). Desmet et al. reported 20.5\% HS with ropivacaine and $23.5 \%$ with ropivacaine plus dexamethasone [13]. Moore and colleagues reported that adverse effects including dyspnoea, hoarseness, HS, and failed block occurred in $8.14 \%$ of patients [36]. Perineural clonidine increases the risk of bradycardia, arterial hypotension, sedation, and it is most likely the result of systemic reabsorption [14]. These typical clonidine related adverse effects are considered as minor harm but may interfere with early mobilization. In this study, a dose of $150 \mu \mathrm{g}$ of clonidine was used which lead to low systolic blood pressure of less than $100 \mathrm{~mm} \mathrm{Hg}$ in three patients with an incidence of $10 \%$ persisting for $4 \mathrm{~h}$ postoperatively. The incidence of sedation was $20 \%$ in clonidine group while $0.03 \%$ in dexamethasone group. Postoperatively catheter related complications were low with three patients (5\%) developing leakage of fluid from the catheter insertion site, out of which two patients had pain relief after trouble shooting the catheter. Three patients (5\%) had catheter dislodgement after surgical intervention. Catheter dislodgement can be attributed to faulty technique of positioning prior to surgical intervention causing stretching of dressing over the catheter leading to dislodgement. Pawa et al. have showed few complications related to the infusion ( $2 \%$ technical and $8 \%$ leakage issues) with low rates 
of catheter dislodgement (1.5\%) and no catastrophic events related to catheter in 1500 patients and apparently no patients returned to hospital because of pain or other problems related to the infusion [37].

The strengths of the study are that it was a prospective, randomized, double blind clinical trial. Randomization is essential in clinical trials to establish a cause and effect relationship for an intervention. Sample size was calculated and adequate number of patients was enrolled for the study. Also, strict inclusion and exclusion criteria were followed during patient selection.

There were a few limitations of the present study. Firstly, it included only ASA physical status I and II patients and results of the study cannot be applied to the patients of higher grade of ASA physical status. Secondly, it did not include measurement of serum ropivacaine and serum clonidine levels. Thirdly, the length of hospital stay and evaluation of long term benefits of pain relief would have been more valuable and would have added more strength to the study. Fourthly, sensory block was not assessed using repeated neurological examination due to difficulty in assessing sensory block after surgery so first analgesic request was used as a proxy measure for the end point of sensory block. However, further multicentric trials with longer study period assessing the blood levels of the two study drugs could be done in future.

\section{Conclusion}

A longer and better postoperative analgesia was observed in patients receiving $8 \mathrm{mg}$ dexamethasone with $30 \mathrm{ml}$ of $0.5 \%$ ropivacaine using ultrasound guided continuous interscalene block as compared to $150 \mu \mathrm{g}$ of clonidine with $30 \mathrm{ml}$ of $0.5 \%$ ropivacaine followed by perineural boluses of ropivacaine $0.2 \%$ by patient controlled regional analgesia. Also, this study showed that dexamethasone when used as an adjunct had more rescue analgesic sparing effect as compared to clonidine, when used in conjunction with $0.5 \%$ ropivacaine during the study period in patients undergoing shoulder surgery.

\section{Funding and Financial Support}

All the required materials for the study were provided by Department of Anaesthesia and Department of Orthopaedics, Government Medical College and Hospital Sector-32, Chandigarh.

\section{References}

1. Middleton C. Understanding the physiological effects of unrelieved pain. Nurs Times. 2003; 99: 28-31.

2. Carr DB, Goudas LC. Acute pain. Lancet Lond Engl. 1999; 353: 2051-2058.

3. Joshi GP, Ogunnaike BO. Consequences of inadequate postoperative pain relief and chronic persistent postoperative pain. Anesthesiol Clin N Am. 2005; 23: 21-36.

4. Kehlet $\mathrm{H}$. Multimodal approach to control postoperative pathophysiology and rehabilitation. Br J Anaesth. 1997; 78: 606-617.

5. Breivik H. Postoperative pain management: why is it difficult to show that it improves outcome? Eur J Anaesthesiol 1998; 15: 748-751.

6. Chung F, Ritchie E, Su J. Postoperative pain in ambulatory surgery. Anesth Analg. 1997; 85: 808-816.

7. Chung F. Recovery pattern and home readiness after ambulatory surgery Anesth Analg. 1995; 80: 896-902.

8. Gold BS, Kitz DS, Lecky JH, Neuhaus JM. Unanticipated admission to the hospital following ambulatory surgery. JAMA 1989; 262: 3008-3010.

9. Kapral S, Greher M, Huber G, Willschke H, Kettner S, Kdolsky R, et al. Ultrasonographic guidance improves the success rate of interscalene brachial plexus blockade. Reg Anesth Pain Med. 2008; 33: 253-258.

10. Aguirre J, Del Moral A, Cobo I, Borgeat A, Blumenthal S. The role of continuous peripheral nerve blocks. Anesthesiol Res Pract 2012; 2012: 560879.

11. Ilfeld BM, Vandenborne K, Duncan PW, Sessler DI, Enneking FK, Shuster $\mathrm{JJ}$, et al. Ambulatory continuous interscalene nerve blocks decrease the time to discharge readiness after total shoulder arthroplasty: a randomized, triplemasked, placebo-controlled study. Anesthesiology. 2006; 105: 999-1007.

12. Rawal N, Allvin R, Axelsson $\mathrm{K}$ et al. Patient-controlled regional analgesia (PCRA) at home - a controlled comparison between bupivacaine and ropivacaine brachial plexus analgesia. Anesthesiology. 2002; 96: 1290-1296.

13. Desmet M, Braems H, Reynvoet M, Plasschaert S, Van Cauwelaert J, Pottel $H$, et al. I.V. and perineural dexamethasone are equivalent in increasing the analgesic duration of a single-shot interscalene block with ropivacaine for shoulder surgery: a prospective, randomized, placebo-controlled study. $\mathrm{Br} J$ Anaesth 2013; 111: 445-452.

14. Popping DM, Elia N, Marret E, Wenk M, Tramer MR. Clonidine as an adjuvant to local anesthetics for peripheral nerve and plexus blocks: a meta-analysis of randomized trials. Anesthesiology 2009; 111: 406-415.

15. Cummings KC, Napierkowski DE, Parra-Sanchez I, Kurz A, Dalton JE, Brems $\mathrm{JJ}$, et al. Effect of dexamethasone on the duration of interscalene nerve blocks with ropivacaine or bupivacaine. Br J Anaesth 2011; 107: 446-453.

16. El Saied AH, Steyn MP, Ansermino JM. Clonidine prolongs the effect of ropivacaine for axillary brachial plexus blockade. Can J Anaesth J. 2000; 47: 962-967.

17. Ramsay MA, Savege TM, Simpson BR, Goodwin R. Controlled sedation with alphaxalone-alphadolone. BMJ 1974; 2: 656-659.

18. Fredrickson MJ, Leightley P, Wong A, Chaddock M, Abeysekera A, Frampton C. An analysis of 1505 consecutive patients receiving continuous interscalene analgesia at home: a multicentre prospective safety study. Anaesthesia. 2016; 71:373-379.

19. Kuthiala G, Chaudhary G. Ropivacaine: A review of its pharmacology and clinical use. Indian J Anaesth. 2011; 55:104-110.

20. Byeon GJ, Shin SW, Yoon JU, Kim EJ, Baek SH, Ri HS. Infusion Methods for Continuous Interscalene Brachial Plexus Block for Postoperative Pain Control after Arthroscopic Rotator Cuff Repair. Korean J Pain. 2015; 28: 210-216.

21. Vorobeichik L, Brull R, Bowry R, Laffey JG, Abdallah FW. Should continuous rather than single-injection interscalene block be routinely offered for major shoulder surgery? A meta-analysis of the analgesic and side-effects profiles. Br J Anaesth. 2018; 120: 679-692.

22. Kawanishi R, Yamamoto $K$, Tobetto $Y$, Kato M, Go R, Tsutsumi $Y M$ et al. Perineural but not systemic low-dose dexamethasone prolongs the duration of interscalene block with ropivacaine: a prospective randomized trial. Local Reg Anesth. 2014; $7:$ 5-9.

23. Johansson A, Hao J, Sjolund B. Local corticosteroid application blocks transmission in normal nociceptive C-fibres. Acta Anaesthesiol Scand. 1990; 34: 335-338.

24. Marks R, Barlow JW, Funder JW. Steroid-induced vasoconstriction: glucocorticoid antagonist studies. J Clin Endocrinol Metab. 1982; 54: 10751077.

25. Shishido H, Kikuchi S, Heckman H, Myers RR. Dexamethasone decreases blood flow in normal nerves and dorsal root ganglia. Spine. 2002; 27:581-586.

26. Yilmaz-Rastoder E, Gold MS, Hough KA, Gebhart GF, Williams BA. Effect of adjuvant drugs on the action of local anesthetics in isolated rat sciatic nerves. Reg Anesth Pain Med. 2012; 37: 403-409.

27. De Oliveira GS, Almeida MD, Benzon HT, McCarthy RJ. Perioperative single dose systemic dexamethasone for postoperative pain: a meta-analysis of randomized controlled trials. Anesthesiology 2011; 115: 575-588.

28. Kirkham KR, Jacot-Guillarmod A, Albrecht E. Optimal Dose of Perineural 
Dexamethasone to Prolong Analgesia after Brachial Plexus Blockade: A Systematic Review and Meta-analysis. Anesth Analg. 2018; 126: 270-279.

29. Murphy DB, McCartney CJ, Chan VW. Novel analgesic adjuncts for brachia plexus block: a systematic review. Anesth Analg. 2000; 90:1122-1128.

30. Bernard JM, Macaire P. Dose-range effects of clonidine added to lidocaine for brachial plexus block. Anesthesiology. 1997; 87:277-284

31. Eisenach JC, De Kock M, Kock M, Klimscha W. Alpha 2-adrenergic agonists for regional anaesthesia: A clinical review of clonidine (1984-1995) Anesthesiology. 1996; 85: 655-674.

32. Butterworth JF, Strichartz GR. The alpha 2-adrenergic agonists clonidine and guanfacine produce tonic and phasic block of conduction in rat sciatic nerve fibers. Anesth Analg. 1993; 76: 295-301

33. Jadon A, Dixit S, Kedia SK, Chakraborty S, Agrawal A, Sinha N. Interscalene brachial plexus block for shoulder arthroscopic surgery: Prospective randomised controlled study of effects of $0.5 \%$ ropivacaine and $0.5 \%$ ropivacaine with dexamethasone. Indian J Anaesth. 2015; 59: 171-176.

34. Breivik H, Borchgrevink PC, Allen SM, Rosseland LA, Romundstad L, Hals EKB, et al. Assessment of pain. Br J Anaesth. 2008; 101:17-24.

35. Singelyn FJ, Seguy S, Gouverneur JM. Interscalene brachial plexus analgesia after open shoulder surgery: continuous versus patient-controlled infusion. Anesth Analg. 1999; 89: 1216-1220.

36. Moore DD, Maerz T, Anderson K. Shoulder Surgeons" Perceptions of Interscalene Nerve Blocks and a Review of Complications, Rates in the Literature". Phys Sportsmed. 2013; 41: 77-84.

37. Pawa A, Devlin AP, Kochhar A. Interscalene catheters - should we give them the cold shoulder? Anaesthesia. 2016; 71: 359-362 